\title{
Determination of Total Antioxidant Capacity of Rapeseed and Its By-Products by a Novel Cerium Oxide Nanoparticle-Based Spectrophotometric Method
}

\author{
Agnieszka Tułodziecka $^{1}$ - Aleksandra Szydłowska-Czerniak ${ }^{1}$
}

Received: 16 December 2015 / Accepted: 6 March 2016/Published online: 2 April 2016

(C) The Author(s) 2016. This article is published with open access at Springerlink.com

\begin{abstract}
The antioxidant capacity (AC) of rapeseed, white flakes, and meal was determined by the novel cerium oxide nanoparticle-based (CeONP) method and a previously described assay based on the formation of silver nanoparticles (AgNP). Antioxidants present in rapeseed and its by-product extracts reduced cerium(IV) ions to red-purple solutions of cerium oxide nanoparticles at $\mathrm{pH}$ 5.6. The influences of time, temperature, $\mathrm{pH}$, and the concentration of the cerium(IV) sulfate solution on cerium oxide nanoparticle generation were estimated. The average $\mathrm{AC}$ of the studied extracts of real samples ranged between 1037 and $3012 \mu \mathrm{mol}$ sinapic acid (SA) $100 \mathrm{~g}^{-1}$ and 3859-12,534 $\mu \mathrm{mol} \mathrm{SA} 100 \mathrm{~g}^{-1}$ for CeONP and AgNP assays, respectively. There is significant, positive correlation between the AC of the examined extracts determined by both analytical methods $(r=0.8189)$. Satisfactory values of relative standard deviation $(\mathrm{RSD}=1.2-3.9 \%)$ and recovery $(95.8-103.3 \%)$ demonstrate a good precision and accuracy of the novel CeONP method for the AC analysis of rapeseed and its byproducts.
\end{abstract}

Keywords Cerium oxide nanoparticles $\cdot$ Antioxidant capacity $\cdot$ Rapeseed $\cdot$ White flakes $\cdot$ Meal

Agnieszka Tułodziecka aaga109@wp.pl

1 Faculty of Chemistry, Nicolaus Copernicus University in Torun, 7 Gagarin Street, 87-100 Toruń, Poland

\section{Introduction}

Nanomaterials have specific biological, thermal, mechanical, optical, electrical, and magnetic properties and can be adapted to the desirable effect by changing their size, shape, and the extent of agglomeration. It has been known that metal and metal oxide nanoparticles, quantum dots, nanowires, nanorods, and carbon nanotubes can be used in analytical chemistry for the preparation of samples, separation, and detection (Vilela et al. 2015b). Currently, nanomaterials are increasingly applied for analysis of the antioxidant potential of various food products (Özyürek et al. 2012; Pelle et al. 2015a, b; Vilela et al. 2015b).

The antioxidants present in food play a very important role in the human body because they are capable of slowing or preventing the oxidation processes. These compounds are involved in the prevention and treatment of cancer, stroke, autism, Alzheimer's dementia, arthritis, aging, cardiovascular disease, Parkinson's disease, and others. Therefore, consumption of natural antioxidants in the daily diet or use of isolated compounds in clinical practices would be beneficial for health. Also, some constituents of oilseeds and vegetable oils such as tocopherols, carotenoids, phytosterols, phytostanols, polyphenols, vitamins, and phospholipids exhibit antioxidant activity (Naczk et al. 1998; Papadopoulos et al. 2003; Pelle et al. 2015a, b; Szydłowska-Czerniak et al. 2012, 2015; Szydłowska-Czerniak and Tułodziecka 2013; Tura et al. 2007). Among them, rapeseed cultivars containing high amounts of antioxidants are one of the most common sources of the healthiest vegetable oil for human consumption in Europe (Kimber and McGregor 1995; Naczk et al. 1998; Nesi et al. 2008). Moreover, during the production of rapeseed oil, by-products such as rapeseed meal and white flakes are formed. Rapeseed meal derived from the rapeseed oil extraction process is rich in protein, with a well-balanced amino acid 
composition; thus, it can be utilized in animal feed and as an organic fertilizer (Khattab and Arntfield 2009; Yoshie-Stark et al. 2008). However, bioactive compounds such as phenolic compounds, tocopherols, vitamin $\mathrm{B}$, and choline and bioelements like calcium, magnesium, zinc, and copper present in meal can be exploited as functional additives (Vuorela et al. 2004). On the other hand, white flakes are an intermediate material for the production of protein concentrates. They contain undenatured proteins, which can be used for the production of the extruded feed possessing high protein dispersibility index and antioxidant level (Maenz 2007). Therefore, bioactive compounds present in rapeseed and its by-products have important biological and chemical properties, which include antioxidant capacity (AC), ability to scavenge active oxygen species and electrophiles, inhibition of nitrosation reactions, and chelating pro-oxidant metals (Shahidi and Ho 2005).

In recent years, different analytical nanoparticle-based methods have been proposed for the assessment of the total $\mathrm{AC}$ of foods and plants. The AC of polyphenol standards, fruit juices, herbal teas, rapeseed varieties, and its products was analyzed by the silver nanoparticle-based (AgNP) method (Özyürek et al. 2012; Szydłowska-Czerniak et al. 2012; Szydłowska-Czerniak and Tułodziecka 2013). However, a gold nanoparticle-based (AuNP) assay was developed for evaluating the $\mathrm{AC}$ of chrysanthemum extracts, various teas, beverages, juice samples, extracts of different parts of plants, fruits of amla and Indian gooseberry, virgin and adulterated argan oils, honey, fresh apples and pears, wines, soybean, and extra virgin olive oils (Choleva et al. 2015; Liu et al. 2012; Pelle et al. 2015a, b; Roy et al. 2011; Scampicchio et al. 2006; Vilela et al. 2012, 2014, 2015a, b; Zougagh et al. 2011). Furthermore, the effect of refining processes on the AC of rapeseed oil was evaluated by the iron oxide nanoparticlebased method (Szydłowska-Czerniak et al. 2015). Also, ceria nanoparticles were utilized to assess the AC of teas and medicinal mushroom samples (Sharpe et al. 2013). In addition, a spectrophotometric method based on the oxidation of the antioxidants present in herbal samples by cerium(IV) sulfate in dilute sulfuric acid at room temperature was reported (Ozyurt et al. 2007, 2010). These same authors applied a spectrofluorometric method based on the reduction of $\mathrm{Ce}^{4+}$ by antioxidants to $\mathrm{Ce}^{3+}$ ions, which exhibited strong fluorescence at $360 \mathrm{~nm}$ with an excitation wavelength of $256 \mathrm{~nm}$ for the AC determination of different teas: green tea bags (Camellia sinensis), nettle herbal tea bags (Urtica dioica/urens), linden tea bags (Tilia), mint tea bags (Mentha spicata), sage herbal tea bags (Salvia officinalis), and chamomile (Matricaria chamomilla L.; Ozyurt et al. 2011).

Nevertheless, there has been no reference on the AC analysis of rapeseed, white flakes, and meal by the cerium oxide nanoparticle-based (CeONP) assay. Therefore, in the present paper, the CeONP method for the AC determination of rapeseed and its by-products was described. The proposed new CeONP method is based on the optical properties of cerium oxide nanoparticles which reveal characteristic absorption bands in the UV-Vis region. The validation of the proposed CeONP method was statistically performed on sinapic acid, the predominant phenolic acid in rapeseed. Moreover, the effects of time, temperature, $\mathrm{pH}$, and the concentration of the cerium(IV) sulfate solution on the cerium reduction assay by a methanolic solution of sinapic acid were evaluated. The $\mathrm{AC}$ results of rapeseed, white flakes, and meal obtained by the novel CeONP method and the previously described AgNP assay were compared and discussed.

\section{Materials and Methods}

\section{Chemicals}

All reagents were of analytical or HPLC grade. Sinapic acid (SA, $98 \%)$, cerium(IV) sulfate tetrahydrate $\left(\mathrm{Ce}\left(\mathrm{SO}_{4}\right)_{2} \cdot 4 \mathrm{H}_{2} \mathrm{O}\right.$, $98 \%)$, and silver nitrate $\left(\mathrm{AgNO}_{3}, 99 \%\right)$ were purchased from Sigma-Aldrich (Poznań, Poland). Acetic acid (99\%), ammonia $(25 \%)$, ammonium nitrate, methanol $(99.8 \%)$, and sodium acetate were obtained from POCH (Gliwice, Poland). Redistilled water was used for the preparation of solutions.

The $8.0-\mathrm{mmol} \mathrm{L}^{-1}$ cerium(IV) sulfate solution was prepared daily in redistilled water and mixed at room temperature for $2 \mathrm{~h}$, obtaining a slightly green-yellow and clear solution. Acetic buffer at $\mathrm{pH} 5.6$ was prepared by adding $4.8 \mathrm{~mL}$ of acetic acid solution $\left(0.2 \mathrm{~mol} \mathrm{~L}^{-1}\right)$ and $45.2 \mathrm{~mL}$ of sodium acetate solution $\left(0.2 \mathrm{~mol} \mathrm{~L}^{-1}\right)$ and diluting redistilled water to $100 \mathrm{~mL}$. Ammonium buffer at $\mathrm{pH} 8.4$ was prepared by dissolving $11.2 \mathrm{~g}$ of ammonium nitrate in redistilled water, adding $1.5 \mathrm{~mL}$ of ammonia solution ( $25 \%$ ), and diluting to $200 \mathrm{~mL}$. The $\mathrm{pH}$ of these buffer solutions was adjusted and checked with a $\mathrm{pH}$ meter.

\section{Instruments}

The UV-Vis spectra were measured using a Hitachi U-2900 (Tokyo, Japan) spectrophotometer in a 1-cm quartz cell. The $\mathrm{pH}$ measurements were made with a $\mathrm{pH}$ meter (Mettler Toledo, SevenGoTM, Warsaw, Poland). The shaker SK-L330-Pro (Medlab, Raszyn, Poland), centrifuge MPW54 (MPW Med. Instruments, Warsaw, Poland), heating plate (Chemland, Stargard Szczeciński, Poland), technical balance WTB 2000 (Radwag, Radom, Poland), analytical balance (OHAUS, Warsaw, Poland), and incubator INP 500 (Memmert, Schwabach, Germany) were used for sample preparation. The cerium oxide deposition process was studied using a scanning electron microscope (SEM; LEO 1460V, Cambridge, UK) and an atomic force microscopy instrument 
(Veeco, Multimode, Nanoscope IIIa Controller, Tapping Mode AFM, Santa Barbara, CA, USA).

\section{Samples}

A winter open-pollinated rapeseed variety of Brassica napus L. (double low, without erucic acid and glucosinolates), rapeseed white flakes, and rapeseed meal were provided by a local vegetable oil factory. White flakes were obtained from the dehulled flaked rapeseed by extracting oil with hexane and flash-desolventizing the defatted rapeseed flakes to minimize protein denaturation. Rapeseed meal was obtained from the dehulled flaked rapeseed by extracting oil with hexane and then desolventizing the defatted flakes by means of hightemperature thermal processing. All samples in the original poly(ethylene terephthalate) packaging were stored at ambient temperature until treatment and further analysis.

\section{Sample Preparation for the Determination of Antioxidant Capacity}

In this study, methanol, methanol-water $(1: 1, v / v)$, and water were used for the extraction of antioxidants from the studied samples. A 2.0-g portion of ground rapeseed, white flakes, and meal and $20 \mathrm{~mL}$ of each solvent with decreasing polarity (dielectric constant $=78.4$ (water), 56.3 (50\% methanol), and 32.6 (methanol)) were transferred into round-bottomed flasks and shaken at room temperature for $20 \mathrm{~min}$. Each sample was extracted in triplicate and the residual flour was separated by centrifugation (4500 rpm, $15 \mathrm{~min}$ ). The pooled extracts were filtered and stored in a refrigerator prior to analysis.

\section{Antioxidant Capacity Determination}

\section{Cerium Oxide Nanoparticle-Based Method}

Exactly $1.0 \mathrm{~mL}$ of $8.0 \mathrm{mmol} \mathrm{L}^{-1}$ cerium(IV) sulfate, $1.0 \mathrm{~mL}$ of acetic buffer (pH 5.6), and $0.5 \mathrm{~mL}$ of methanolic, $50 \%$ methanolic, or aqueous extract of each sample were placed into a $10-\mathrm{mL}$ volumetric flask and made up to volume with redistilled water. After $30 \mathrm{~min}$, the absorbance of a clear redpurple solution was measured at $510 \mathrm{~nm}$ against a reagent blank $\left(1.0 \mathrm{~mL}\right.$ of $8.0 \mathrm{mmol} \mathrm{L}^{-1}$ cerium(IV) sulfate and $1.0 \mathrm{~mL}$ of acetic buffer and made up to $10 \mathrm{~mL}$ with redistilled water).

The influence of time and temperature on $\mathrm{Ce}^{4+}$ reduction by a methanolic solution of sinapic acid was estimated. For this purpose, $1.0 \mathrm{~mL}$ of $8.0 \mathrm{mmol} \mathrm{L}^{-1}$ cerium(IV) sulfate, $1.0 \mathrm{~mL}$ of acetic buffer $(\mathrm{pH} 5.6)$, and $1.5 \mathrm{~mL}$ of $0.6 \mu \mathrm{mol} \mathrm{SA} \mathrm{mL}{ }^{-1}$ were placed into a $10-\mathrm{mL}$ volumetric flask, made up to volume with redistilled water, incubated at $20,40,60,80$, and $100{ }^{\circ} \mathrm{C}$ for $30 \mathrm{~min}$, and the absorbance measured at $510 \mathrm{~nm}$ against a reagent blank. The change of color intensity at $\lambda=510 \mathrm{~nm}$ in time varying from 0 to 120 min was evaluated. Also, the effect of $\mathrm{pH}$ on cerium oxide nanoparticle synthesis was determined by adjusting the $\mathrm{pH}$ of the reaction mixtures $\left(1 \mathrm{~mL}\right.$ of $8.0 \mathrm{mmol} \mathrm{L}^{-1}$ cerium(IV) sulfate and $1 \mathrm{~mL}$ of $0.6 \mu \mathrm{mol} \mathrm{mL}{ }^{-1}$ sinapic acid) to $3.6,4.6,5.6$, 7.0, 7.6, 8.6, and 9.6 using acetic and ammonium buffers. Moreover, the impact of different concentrations of cerium(IV) sulfate solutions on the formation of cerium oxide nanoparticles was studied as follows: $1.0 \mathrm{~mL}$ of acetic buffer (pH 5.6), $2.0 \mathrm{~mL}$ of $0.6 \mu \mathrm{mol} \mathrm{mL} \mathrm{m}^{-1}$ sinapic acid, and 0.25 , $0.50,1.00,1.50$, and $2.00 \mathrm{~mL}$ of $8.0 \mathrm{mmol} \mathrm{L}^{-1} \mathrm{Ce}\left(\mathrm{SO}_{4}\right)_{2}$ were placed into $10-\mathrm{mL}$ volumetric flasks, respectively, and made up to the mark with redistilled water.

\section{Silver Nanoparticle-Based Method}

The AC of the studied rapeseed, white flakes, and meal was determined by the AgNP spectrophotometric method, as described in our previous study (Szydłowska-Czerniak et al. 2012). Briefly, $0.2 \mathrm{~mL}$ of methanolic, $50 \%$ methanolic, or aqueous extract of each sample, $1.0 \mathrm{~mL}$ of ammonium buffer (pH 8.4), and $1.0 \mathrm{~mL}$ of $10 \mathrm{mmol} \mathrm{L}^{-1}$ silver nitrate were placed into a $10-\mathrm{mL}$ volumetric flask and made up to volume with redistilled water. After $60 \mathrm{~min}$, the absorbance of a yellow-orange solution was measured at $405 \mathrm{~nm}$ against a reagent blank $(1.0 \mathrm{~mL}$ of ammonium buffer and $1.0 \mathrm{~mL}$ of $10 \mathrm{mmol} \mathrm{L}^{-1}$ silver nitrate made up to $10 \mathrm{~mL}$ with redistilled water).

Calibration curves were prepared using working solutions of sinapic acid in methanol between 0.03 and $0.21 \mu \mathrm{mol} \mathrm{mL} \mathrm{m}^{-1}$. The least-squares method was applied to calculate the line equation: $A_{405}$ [a.u.] $=(4.34 \pm 0.14) \times c_{\mathrm{SA}}$ $\left[\mu \mathrm{mol} \mathrm{mL}{ }^{-1}\right]-(0.021 \pm 0.019)$, resulting in a linear correlation coefficient $(r=0.9974), \mathrm{RSD}_{\text {slope }}=1.57 \%(n=5)$, and molar extinction coefficient $\left(\varepsilon=4.1 \times 10^{3} \mathrm{~L} \mathrm{~mol}^{-1} \mathrm{~cm}^{-1}\right)$ for sinapic acid.

\section{Scanning Electron Microscopy and Atomic Force Microscopy Analyses}

The $1.0 \mathrm{~mL}$ of $8.0 \mathrm{mmol} \mathrm{L}^{-1}$ cerium(IV) sulfate, $1.0 \mathrm{~mL}$ of acetate buffer (pH 5.6), and $0.5 \mathrm{~mL}$ of rapeseed meal extract prepared in $50 \%$ methanol were transferred into a $10-\mathrm{mL}$ volumetric flask and made up to volume with redistilled water. The mixture was kept in the dark for $30 \mathrm{~min}$ at ambient temperature. The silicon wafer was immersed in the prepared solution containing cerium oxide nanoparticles and immediately placed in a furnace at $180{ }^{\circ} \mathrm{C}$ for $16 \mathrm{~h}$. The morphology of the obtained cerium oxide nanoparticles was visualized by scanning electron microscopy (SEM) and atomic force microscopy (AFM). 


\section{Statistical Analysis}

The AC results determined by the proposed CeONP and AgNP methods were presented as mean values $(n-$ $=5) \pm$ standard deviation (SD). Differences between AC means were detected using Duncan test $(p<0.05)$. The within-day precision of the analytical methods was expressed as the relative standard deviation (RSD, in percent). Moreover, Pearson correlation test was used to assess the relationship between the AC of the studied extracts of rapeseed, white flakes, and meal analyzed by both analytical methods. Furthermore, the accuracy of the novel method (CeONP) was determined using a recovery test. For this purpose, a fixed amount of sinapic acid standard solution $\left(0.03 \mu \mathrm{mol} \mathrm{mL} L^{-1}\right)$ was added to extracts of the analyzed samples and the percent recovery was calculated as follows: [AC of spiked extract/(AC of extract $+0.03 \mu \mathrm{mol} \mathrm{mL} \mathrm{m}^{-1}$ of sinapic acid solution) $] \times 100 \%$.

\section{Results and Discussion}

\section{Characteristics of the Novel CeONP Method}

The following reaction mechanism of cerium ion reduction by sinapic acid was proposed for a new CeONP assay:<smiles>COC1=CC(C(=O)O)C=C(OC)C1=O</smiles>

It can be noted that sinapic acid possesses a phenolic nucleus and an unsaturated side chain, which can be oxidized by cerium(IV) sulfate in acidic medium (pH 5.6). The hydroxyl group in the aromatic ring and the alkene bond of sinapic acid were oxidized easily and the corresponding quinone structure and oxalic acid were formed, respectively (Wang et al. 2008). At the same time, cerium ions were reduced to $\mathrm{Ce}_{x} \mathrm{O}_{y}$ nanoparticles, resulting in the strong signal in visible range (Fig. 1).

The absorption peak at $510 \mathrm{~nm}$ was not observed in the UV-Vis spectra of $0.060 \mu \mathrm{mol} \mathrm{mL} \mathrm{m}^{-1}$ sinapic acid solution and $0.8 \mathrm{mmol} \mathrm{L}^{-1}$ cerium(IV) sulfate solution. The presence of a characteristic absorbance band at $510 \mathrm{~nm}$ indicates the generation of cerium oxide nanoparticles (Fig. 1).

Cerium oxide nanoparticles have the ability to undergo a facile conversion between $\mathrm{Ce}$ (IV) and Ce(III) oxidation states.

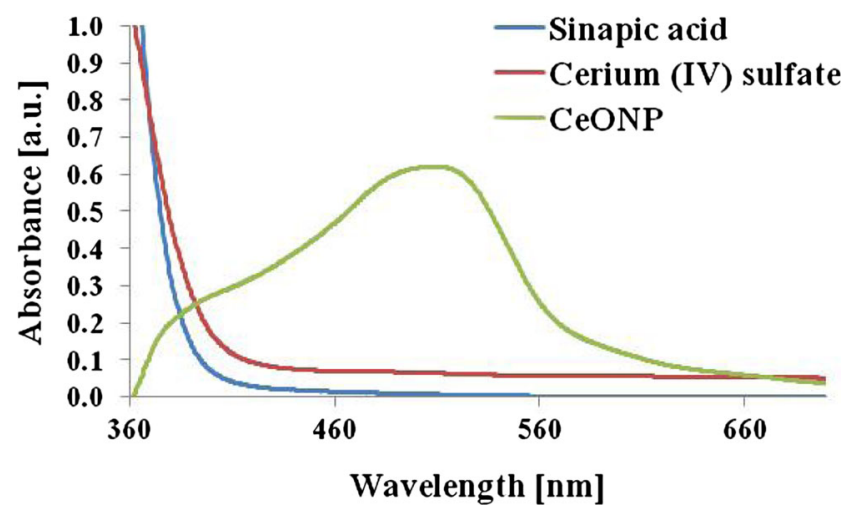

Fig. $1 \mathrm{UV}-$ Vis spectra of $0.045 \mu \mathrm{mol} \mathrm{mL} \mathrm{m}^{-1}$ sinapic acid solution, $0.8 \mathrm{mmol} \mathrm{L}^{-1}$ cerium(IV) sulfate solution, and cerium oxide nanoparticles

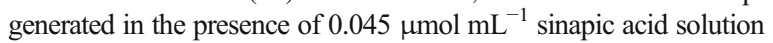

Probably, the tetravalent $\mathrm{Ce}$ ions were reduced in a reducing medium (presence of antioxidants) to trivalent $\mathrm{Ce}$ ions and the red-purple color indicates the presence of $\mathrm{Ce}_{2} \mathrm{O}_{3}$ nanoparticles. It is evident that all $\mathrm{Ce}$ (III) ions were not oxidized during the reaction time and conditions. Some $\mathrm{Ce}$ ions remained as trivalent ions and were introduced into the cavity and formed the $\mathrm{Ce}_{2} \mathrm{O}_{3}$ nanoparticles (Okuda et al. 2011). The higher portion of $\mathrm{Ce}^{3+}$ having the deficiency of positive charge causes more intrinsic defects in the cerium oxide structure, which can be compensated by oxygen vacancies. This fact suggests that cerium oxide is an oxygen-deficient, non-stoichiometric oxide $\left(\mathrm{CeO}_{2-x}\right.$, with $0<x \leq 0.5$; Samiee and Goharshadi 2012). Moreover, an increase in the $\mathrm{Ce}^{+3}$ valance state with decreasing particle size was observed (Korsvik et al. 2007; Naganuma and Traversa 2012). Therefore, the size of cerium oxide nanoparticles depends on the ratio of $\mathrm{Ce}(\mathrm{III}) / \mathrm{Ce}(\mathrm{IV})$ and the intensive red-purple color confirms the generation of smaller non-stoichiometric cerium oxide nanoparticles (Ornatska et al. 2011). Although the presence of sulfate ions in a solution can accelerate the agglomeration of these nanoparticles (Masui et al. 2002).

As can be seen in Fig. 2, time, temperature, $\mathrm{pH}$, and the concentration of the cerium(IV) sulfate solution affected the reducing properties of sinapic acid.

The color change can be observed in the methanolic solutions of sinapic acid $\left(c=0.090 \mu \mathrm{mol} \mathrm{mL} \mathrm{m}^{-1}\right)$ after incubation with $\mathrm{Ce}\left(\mathrm{SO}_{4}\right)_{2}$ solution $\left(c=0.8 \mathrm{mmol} \mathrm{L}^{-1}\right)$ in $\mathrm{pH} 5.6$ at 0 $120 \mathrm{~min}$. It is noteworthy that cerium oxide nanoparticle formation significantly enhanced as the contact time was extended to $30 \mathrm{~min}$, but after that, only a slight variation of the absorbance at $510 \mathrm{~nm}$ could be seen (Fig. 2a). Moreover, the 

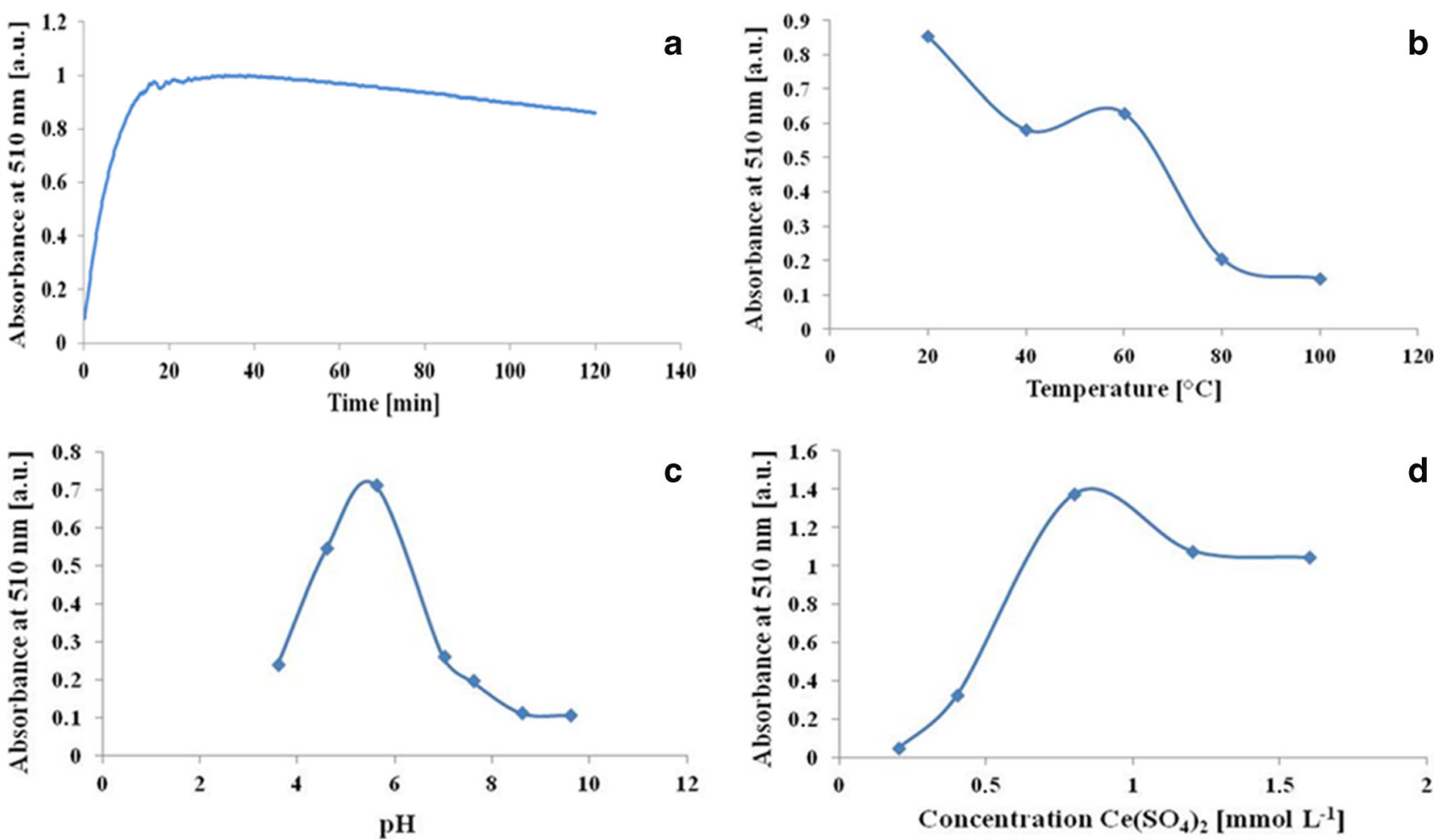

Fig. 2 Effect of time (a), temperature (b), $\mathrm{pH}(\mathbf{c})$, and concentration of $\mathrm{Ce}\left(\mathrm{SO}_{4}\right)_{2}(\mathbf{d})$ on the absorbance at $510 \mathrm{~nm}$ of the formed cerium oxide nanoparticles

incubation temperature of the reaction mixtures had an impact on the generation of cerium oxide nanoparticles. At lower temperatures $\left(20,40\right.$, and $\left.60^{\circ} \mathrm{C}\right)$, solutions of cerium oxide nanoparticles revealed red-purple and light red colors, whereas the light pink and orange colors were characteristic for solutions incubated at 80 and $100{ }^{\circ} \mathrm{C}$ (Fig. 2b). It can be noted that the rate of cerium oxide nanoparticle formation reduced with the increase of the reaction temperature to $40{ }^{\circ} \mathrm{C}$ (Fig. 2b). The slight increase in the absorbance at $510 \mathrm{~nm}$ was observed as the temperature increases to $60^{\circ} \mathrm{C}$. Further increase of temperature to $100{ }^{\circ} \mathrm{C}$ caused a decrease in the formation of cerium oxide nanoparticles (Fig. 2b). One possible explanation for this fact is a decrease in the antioxidant efficiency of sinapic acid, responsible for the reduction of $\mathrm{Ce}^{4+}$ ions, as well as the agglomeration of nanoparticles.

In addition, the absorbance at $\lambda=510 \mathrm{~nm}$ continuously increased along with the $\mathrm{pH}$ increase to 5.6, suggesting progressive generation of cerium oxide nanoparticles (Fig. 2c). However, a further $\mathrm{pH}$ increase up to 9.6 reduced the absorbance. This fact indicated that Ce(IV) oxyhydroxides at elevated $\mathrm{pH}$ were formed. Evidently, the $\mathrm{pH}$ value of the solution affects the $\mathrm{Ce}^{3+} / \mathrm{Ce}^{4+}$ conversion and cerium oxide nanoparticle morphology. At a low $\mathrm{pH}$, the reaction mainly involves $\mathrm{Ce}(\mathrm{III})$ oxidation and $\mathrm{Ce}(\mathrm{IV})$ reduction, whereas at higher $\mathrm{pH}$, only $\mathrm{Ce}$ (III) oxidation occurs; thus, a high $\mathrm{pH}$ value favors $\mathrm{Ce}(\mathrm{III})$ oxidation. This suggests that oxidation from $\mathrm{Ce}^{3+}$ to $\mathrm{Ce}^{4+}$ is easier in an alkaline solution. In addition, the decrease of the $\mathrm{pH}$ value causes the increase of $\mathrm{Ce}^{4+}$ solubility from the $\mathrm{CeO}_{2}$ nuclei, which can induce an increased dissolution/ precipitation process and the formation of crystals with sharp corners and edges. The solubility of $\mathrm{CeO}_{2}$ decreases with the $\mathrm{pH}$ increase, and particles with more surface defects were generated. However, the hydrated cerium oxide nanoparticles possess both acidic and alkaline characteristics: due to the loss of protons, their surface demonstrates negative charges at alkaline conditions - hydrogen ions can be gained from oxygen anions as well - and reveals positive charges at acidic solution (Bumajdad et al. 2009; Lin et al. 2012; Yan et al. 2007).

Furthermore, the amount of cerium oxide nanoparticles would become negligible if the concentration of the $\mathrm{Ce}\left(\mathrm{SO}_{4}\right)_{2}$ solution was low. The increase of the $\mathrm{Ce}\left(\mathrm{SO}_{4}\right)_{2}$ concentration to $0.8 \mathrm{mmol} \mathrm{L}^{-1}$ increased the production of cerium oxide nanoparticles; therefore, the absorbance at $510 \mathrm{~nm}$ gradually enhanced. However, reduction of the absorbance due to the agglomeration of cerium oxide nanoparticles formed by more concentrated $\mathrm{Ce}\left(\mathrm{SO}_{4}\right)_{2}$ solutions, as well as the hydrolysis of $\mathrm{Ce}^{4+}$ ions proportional to their concentration, was observed (Fig. 2d).

Therefore, the proposed CeONP method can be effectively used for $\mathrm{AC}$ determination under the following conditions: the reaction mixture of $1.0 \mathrm{~mL}$ of $8.0 \mathrm{mmol} \mathrm{L}^{-1}$ cerium(IV) sulfate, $1.0 \mathrm{~mL}$ of acetic buffer ( $\mathrm{pH} 5.6$ ), and $0.5 \mathrm{~mL}$ of sample extracts should be made up to $10 \mathrm{~mL}$ with redistilled water and incubated at room temperature $\left(20^{\circ} \mathrm{C}\right)$ for $30 \mathrm{~min}$. 
The novel CeONP method was evaluated with respect to linearity, precision, accuracy, sensitivity, and limits of detection (DL) and quantification (QL). Five calibration curves for the new CeONP method were obtained by diluting the corresponding stock solution $\left(0.6 \mu \mathrm{mol} \mathrm{mL}{ }^{-1}\right)$ of sinapic acid between 0.006 and $0.090 \mu \mathrm{mol} \mathrm{mL} \mathrm{L}^{-1}$ and plotted on the same day. The least-squares method was applied to calculate the line equation: $A_{510}$ [a.u.] $=(10.42 \pm 0.12) \times c_{\mathrm{SA}}\left[\mu \mathrm{mol} \mathrm{mL} \mathrm{mL}^{-1}\right]+$ $(0.048 \pm 0.007)$, resulting in a linear correlation coefficient $(r=0.9996)$ and $\mathrm{RSD}_{\text {slope }}=2.8 \%(n=5)$. The AC results were expressed in micromoles SA equivalents per $100 \mathrm{~g}$ of sample. The within-day precision of the CeONP method was tested by analysis of a sample containing $0.060 \mu \mathrm{mol} \mathrm{SA} \mathrm{mL}{ }^{-1}$ in five replicates. The obtained value of $\mathrm{RSD}=3.6 \%$ indicates reasonable repeatability of the proposed new assay. Moreover, the calculated detection $\left(\mathrm{DL}=2.75 \times 10^{-3} \mu \mathrm{mol} \mathrm{SA} \mathrm{mL} \mathrm{mL}^{-1}\right.$ ) and quantification $\left(\mathrm{QL}=9.17 \times 10^{-3} \mu \mathrm{mol} \mathrm{SA} \mathrm{mL} \mathrm{S}^{-1}\right)$ limits confirm the linearity of the concentration range for $\mathrm{AC}$ determination. The CeONP method appeared to be sensitive $\left(\varepsilon=1.24 \times 10^{4} \mathrm{~L} \mathrm{~mol}^{-1} \mathrm{~cm}^{-1}\right.$ for sinapic acid).

The formation of cerium oxide nanoparticles in the studied system was confirmed by the AFM and SEM analyses and presented in Fig. 3.

The AFM and SEM images revealed that cerium oxide nanoparticles appear elliptical and rod-shaped (Fig. 3a, b). The characteristic peaks for cerium and oxygen observed on the EDX spectrum confirm the formation of cerium oxide nanoparticles (Fig. 3c). Also, signal from carbon caused by polyphenol groups and other C-containing compounds in rapeseed meal was displayed. In addition, the presence of the $\mathrm{S}$ signal can be explained as the residue of the sulfate groups, whereas the Si signal originates from the substrate of the silicon wafer. Other impurities were not detected (Fig. 3c).

The UV-Vis spectrum (Fig. 1) and AFM and SEM-EDX analyses (Fig. 3) demonstrated the formation of cerium oxide nanoparticles.

\section{Antioxidant Capacity of Real Samples}

The AC of rapeseed, white flakes, and meal was determined by a new CeONP method and compared with the results obtained by the AgNP assay (Table 1).

The AC results of the studied samples indicate significant differences (Duncan test, Table 1), although the AC values of rapeseed and meal methanolic extracts determined by the AgNP method did not differ significantly. Moreover, insignificant differences between the CeONP and AgNP results for extracts of rapeseed and meal, respectively, prepared in $50 \%$ methanol and water were observed. Also, the ACs of methanolic and aqueous extracts of meal analyzed by the novel CeONP method were not significantly different (Duncan test, $p>0.05$ ).
It is noteworthy that the CeONP values (1037$3012 \mu \mathrm{mol} \mathrm{SA} 100 \mathrm{~g}^{-1}$ ) were significantly lower in comparison with the AgNP results (3859-12,534 $\mu \mathrm{mol} \mathrm{SA} 100 \mathrm{~g}^{-1}$ ) for the examined extracts. This fact can be explained by the analyzed extracts containing antioxidant compounds more capable of reducing $\mathrm{Ag}^{+}$to silver nanoparticles than $\mathrm{Ce}^{4+}$ to cerium oxide nanoparticles, although the applied methods (AgNP and CeONP) are based on the same reaction mechanism and measure the ability of rapeseed antioxidants to transfer one electron to reduce silver and cerium(IV) ions, respectively, which form the colored silver and cerium oxide nanoparticles. However, the formation of silver and cerium oxide nanoparticles depends on the concentration, oxidation potential, and chemical structure of antioxidants, as well as the reaction medium conditions.

The water extract of rapeseed revealed the lowest CeONP and AgNP values, while the ACs of white flakes and meal determined by both analytical methods were the lowest for $50 \%$ methanolic extracts (Table 1). On the other hand, the methanolic extracts of rapeseed, white flakes, and meal presented the highest CeONP (1304-3012 $\left.\mu \mathrm{mol} \mathrm{SA} 100 \mathrm{~g}^{-1}\right)$ and AgNP (9771-12,534 $\mu$ mol SA $100 \mathrm{~g}^{-1}$ ) values. This suggests that methanol was the most effective solvent for the extraction of antioxidants from the studied samples; thus, the AC did not increase proportionally with solvent polarity. For comparison, the $\mathrm{AC}$ values of water extracts of herbal and tea samples determined by CERAC assay and ceria sensors varied from 9000 to $105,000 \mu \mathrm{mol} 100 \mathrm{~g}^{-1}$ depending on the type of sample and its variety (Ozyurt et al. 2007; Sharpe et al. 2013). Although, Özyürek et al. (2012) obtained significantly lower AC results (200-3400 $\left.\mu \mathrm{mol} 100 \mathrm{~g}^{-1}\right)$ for some commercial fruit juices applying the SNPAC method based on the reduction of $\mathrm{Ag}^{+}$ions in the presence of citrate-stabilized silver seeds. Moreover, in our previous reports, $50 \%$ methanolic extracts of different rapeseed cultivars revealed AgNP values (5261-9462 $\mu \mathrm{mol} \mathrm{SA} 100 \mathrm{~g}^{-1}$ ) similar to that $\left(8629 \mu \mathrm{mol} \mathrm{SA} 100 \mathrm{~g}^{-1}\right)$ for the studied winter openpollinated rapeseed variety (Szydłowska-Czerniak et al. 2012; Szydłowska-Czerniak and Tułodziecka 2013). However, the AgNP values of the methanolic extracts of rapeseed $\left(10,129 \mu \mathrm{mol} \mathrm{SA} 100 \mathrm{~g}^{-1}\right)$ and meal (9771 $\mu \mathrm{mol} \mathrm{SA} 100 \mathrm{~g}^{-1}$ ) were higher in comparison with those (7350 and $8830 \mu \mathrm{mol} \mathrm{SA} 100 \mathrm{~g}^{-1}$, respectively) obtained previously (Szydłowska-Czerniak et al. 2012). On the contrary, the aqueous extract of rapeseed had a somewhat lower AgNP value $\left(5287 \mu \mathrm{mol} \mathrm{SA} 100 \mathrm{~g}^{-1}\right)$ than earlier reported (5720 $\mu \mathrm{mol} \mathrm{SA} 100 \mathrm{~g}^{-1}$; Szydłowska-Czerniak et al. 2012). Moreover Szydłowska-Czerniak et al. (2012) found about two times higher the AgNP for meal prepared in $50 \%$ methanol and water (10,560 and $7180 \mu \mathrm{mol} \mathrm{SA} 100 \mathrm{~g}^{-1}$, respectively).

It is noteworthy that the RSD values for the novel CeONP method (1.2-3.9\%) were comparable to those obtained by the AgNP (0.5-4.2\%) assay. These results suggest that the used 

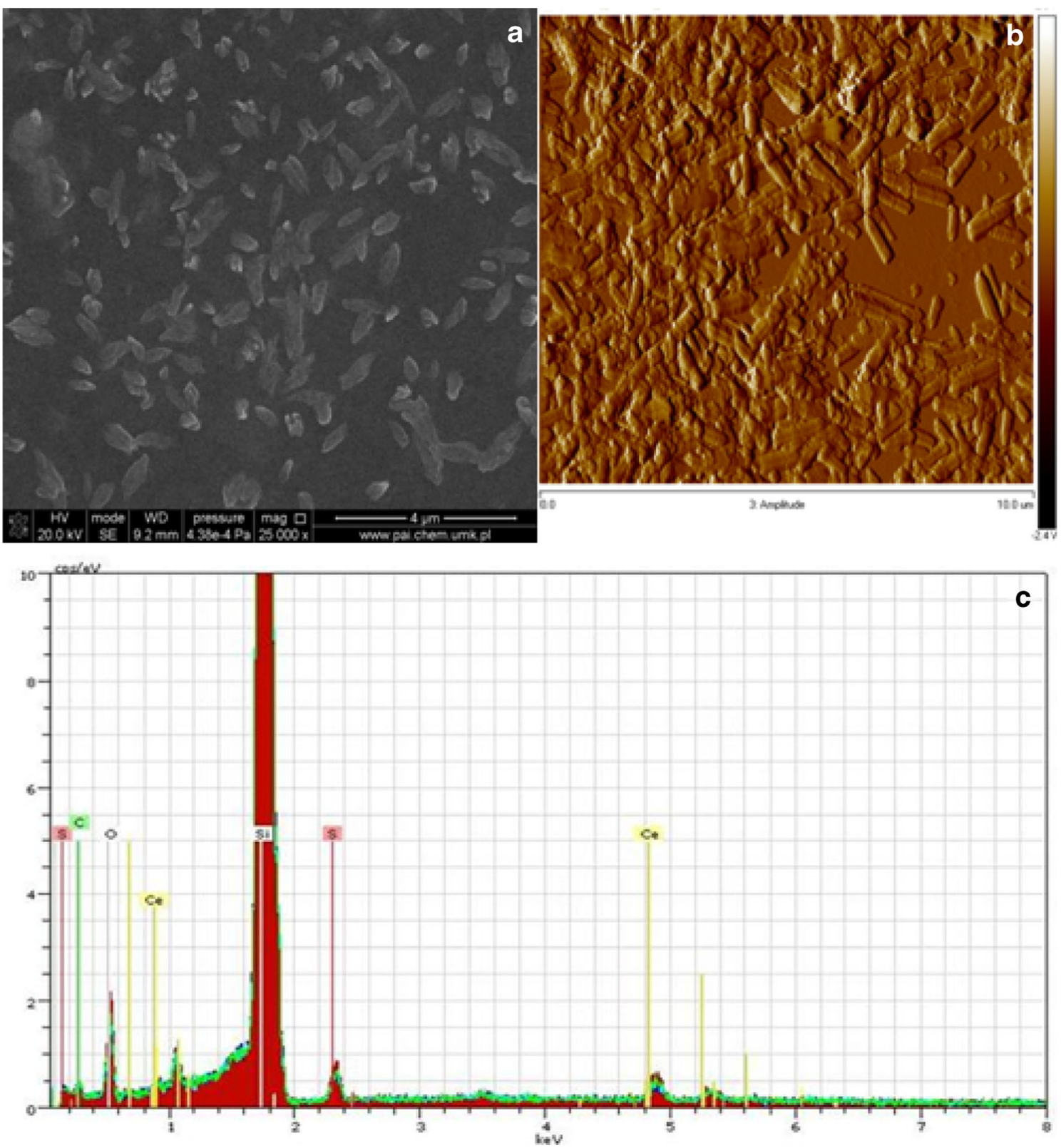

Fig. 3 SEM (a) and AFM (b) micrographs and EDX spectrum (c) of the cerium oxide nanoparticles obtained from rapeseed meal extract

analytical methods based on metal oxide and metal nanoparticle formation can be applicable to the determination of the total antioxidant potential of rapeseed and its by-products, with good repeatability.

For comparison, Ozyurt et al. (2007) calculated a higher value of $\mathrm{RSD}=6.62 \%$ during the $\mathrm{AC}$ determination of the water extract of nettle by the CERAC method, whereas similar RSD results (1.4-5.0 \%) were found for nettle, rosehip extracts, and various teas analyzed by the modified CERAC method and spectrofluorometric method based on Ce(IV) reduction (Ozyurt et al. 2010, 2011).

Also, a recovery test was performed for the accuracy evaluation of the new CeONP method. The recovery identifies a ratio between the quantity of analyte, experimentally determined in known concentration material, and the expected value. The results of the recovery test were listed in Table 2.

The recovery efficiency of sinapic acid added to methanolic, $50 \%$ methanolic, and aqueous extracts of rapeseed, white flakes, and meal ranged between $95.8 \%$ for the aqueous extract of rapeseed and $103.3 \%$ for $50 \%$ methanolic extract of meal (Table 2). These results indicate that the AC can be determined with good accuracy by the proposed CeONP method.

Also, Özyürek et al. (2012) and Szydłowska-Czerniak et al. (2012) calculated similar mean recoveries $(92.3-104.6 \%$ ) for the $\mathrm{AC}$ of green tea, olive oil, as well as ethanolic, $50 \%$ 
Table 1 Antioxidant capacity of real samples

\begin{tabular}{|c|c|c|c|}
\hline \multirow[t]{2}{*}{ Sample } & \multicolumn{3}{|c|}{ Antioxidant capacity ${ }^{\mathrm{a}} \pm \mathrm{SD}\left(\mu \mathrm{mol}\right.$ SA $\left.100 \mathrm{~g}^{-1}\right)$} \\
\hline & Methanolic extract & $\begin{array}{l}\text { Methanolic-aqueous } \\
(1: 1, v / v) \text { extract }\end{array}$ & Aqueous extract \\
\hline \multicolumn{4}{|l|}{ CeONP method } \\
\hline Rapeseed & $2069 \pm 71^{\mathrm{b}, \mathrm{y}}$ & $1919 \pm 69^{\mathrm{c}, \mathrm{x}}$ & $1804 \pm 24^{\mathrm{b}, \mathrm{x}}$ \\
\hline White flakes & $3012 \pm 35^{\mathrm{c}, \mathrm{z}}$ & $1472 \pm 35^{\mathrm{b}, \mathrm{x}}$ & $2495 \pm 91^{\mathrm{c}, \mathrm{y}}$ \\
\hline Meal & $1304 \pm 38^{\mathrm{a}, \mathrm{y}}$ & $1037 \pm 18^{\mathrm{a}, \mathrm{x}}$ & $1270 \pm 50^{\mathrm{a}, \mathrm{y}}$ \\
\hline \multicolumn{4}{|l|}{ AgNP method } \\
\hline Rapeseed & $10,129 \pm 120^{\mathrm{d}, \mathrm{z}}$ & $8629 \pm 161^{\mathrm{f}, \mathrm{y}}$ & $5287 \pm 189^{\mathrm{e}, \mathrm{x}}$ \\
\hline White flakes & $12,534 \pm 522^{\mathrm{e}, \mathrm{z}}$ & $6154 \pm 235^{\mathrm{e}, \mathrm{x}}$ & $11,556 \pm 393^{\mathrm{f,y}}$ \\
\hline Meal & $9771 \pm 378^{\mathrm{d}, \mathrm{y}}$ & $3859 \pm 18^{\mathrm{d}, \mathrm{x}}$ & $4232 \pm 123^{\mathrm{d}, \mathrm{x}}$ \\
\hline
\end{tabular}

Different letters (a-f) within the same column indicate significant differences between CeONP and AgNP of all the studied samples. Different letters $(\mathrm{x}-\mathrm{z})$ within the same row indicate significant differences between the AC of each sample extract prepared in solvents with different dielectric constants (one-way ANOVA and Duncan test, $p<0.05)$

${ }^{a}$ Values are the mean \pm standard deviation $(n=5, p=0.05)$ methanolic, and aqueous extracts of rapeseed and its products analyzed by the AgNP method.

\section{Correlation Between the CeONP and AgNP Methods}

The relationship between the AC of the studied extracts of rapeseed, white flakes, and meal determined by both analytical methods based on the formation of cerium oxide and silver nanoparticles was estimated using regression analysis. The obtained AC results suggest that there are high positive correlations between the novel CeONP and AgNP assays ( $r=0.9413, r=0.9999$, and $r=0.9505$ for methanolic, $50 \%$ methanolic, and aqueous extracts, respectively).

Also, the AC analyzed by the proposed CeONP assay and the results for all the studied extracts obtained by the AgNP method were correlated significantly $(r=0.8189, p=0.0069)$.

This can be explained by the fact that all examined extracts were rich sources of antioxidants capable of the reduction of $\mathrm{Ce}(\mathrm{IV})$ and $\mathrm{Ag}(\mathrm{I})$ to suitable nanoparticles at the same time, which can be indicated by the characteristic bands in visible range.

For comparison, significantly lower correlation coefficients for the relationships between the CERAC-CUPRAC and CERAC-ABTS results ( $r=0.666$ and $r=0.731$, respectively) of nine antioxidant compounds were calculated by Ozyurt et al. (2007). Also, lower values of $r=0.5971-0.9149$ between the AgNP and FRAP, DPPH, and total phenolic content in different extracts of rapeseed, flakes, press cake, and meal were demonstrated in our previous papers (SzydłowskaCzerniak et al. 2012; Szydłowska-Czerniak and Tułodziecka 2013). However, a higher correlation coefficient $(r=0.936)$ was found between the silver nanoparticle-based (SNPAC) and the CUPRAC methods (Özyürek et al. 2012).

\section{Conclusion}

A novel spectrophotometric CeONP method for the AC evaluation of rapeseed and its by-products based on the generation of cerium oxide nanoparticles was developed for the first time. The redox reaction produces non-stoichiometric cerium oxide nanoparticle solutions at room temperature and $\mathrm{pH}$ 5.6, and their optical absorption peak was detected at $510 \mathrm{~nm}$. However, the formation of cerium oxide nanoparticles depends on the time, temperature, $\mathrm{pH}$ of the reaction mixture, and the concentration of cerium(IV) sulfate. The proposed CeONP method is simple, rapid, and low-cost, but precise, accurate, and sensitive, and it can be used by industrial

Table 2 Recovery test for the novel CeONP method

\begin{tabular}{|c|c|c|c|c|c|c|c|c|c|c|}
\hline \multirow{3}{*}{$\begin{array}{l}\text { Solvent } \\
\text { Methanol }\end{array}$} & \multicolumn{3}{|c|}{$\begin{array}{l}\text { Antioxidant capacity of extracts } \\
{\left[\mu \mathrm{mol} \mathrm{mL} L^{-1}\right]}\end{array}$} & \multirow{3}{*}{$\begin{array}{l}\text { Concentration of sinapic } \\
\text { acid }\left(\mu \mathrm{mol} \mathrm{mL}^{-1}\right) \\
0.03\end{array}$} & \multicolumn{6}{|c|}{$\begin{array}{l}\text { Antioxidant capacity of the fortified extracts (Recovery, \%) } \\
\left(\mu \mathrm{mol} \mathrm{mL} \mathrm{mL}^{-1}\right)\end{array}$} \\
\hline & \multirow{2}{*}{$\begin{array}{l}\text { Rapeseed } \\
0.0385\end{array}$} & \multirow{2}{*}{$\begin{array}{l}\text { White flakes } \\
0.0415\end{array}$} & \multirow{2}{*}{$\frac{\text { Meal }}{0.0244}$} & & \multicolumn{2}{|c|}{ Rapeseed } & \multicolumn{2}{|c|}{ White flakes } & \multicolumn{2}{|l|}{ Meal } \\
\hline & & & & & 0.0700 & (102.1) & 0.0736 & (102.9) & 0.0550 & (101.2) \\
\hline $50 \%$ methanol & 0.0294 & 0.0363 & 0.0196 & 0.03 & 0.0583 & $(98.2)$ & 0.0676 & (101.9) & 0.0512 & (103.3) \\
\hline Water & 0.0353 & 0.0524 & 0.0165 & 0.03 & 0.0626 & $(95.8)$ & 0.0791 & $(96.0)$ & 0.0453 & $(97.4)$ \\
\hline
\end{tabular}


laboratories equipped with a spectrophotometer. The novel CeONP method revealed a satisfactory, intra-day precision (RSD $=1.2-3.9 \%)$ comparable to that of the AgNP method $(\mathrm{RSD}=0.5-4.2 \%)$ and higher sensitivity $\left(\varepsilon=1.24 \times 10^{4}\right.$ and $4.1 \times 10^{3} \mathrm{~L} \mathrm{~mol}^{-1} \mathrm{~cm}^{-1}$ for the CeONP and AgNP methods for sinapic acid, respectively).

Therefore, the new CeONP method is an alternative procedure for these based on the formation of metal nanoparticles such as AgNP, and it can be applied by oil industry laboratories for the $\mathrm{AC}$ assessment of oilseeds, semi-products, final products, and by-products.

\section{Compliance with Ethical Standards}

Funding This work was supported by the National Science Center of Poland grant no. DEC-2013/09/N/NZ9/01451.

Conflict of Interest Agnieszka Tułodziecka declares that she has no conflict of interest. Aleksandra Szydłowska-Czerniak declares that she has no conflict of interest.

Ethical Approval This article does not contain any studies with human participants or animals performed by any of the authors.

Informed Consent The authors named in the manuscript are entitled to the authorship and have approved the final version of the submitted manuscript.

Open Access This article is distributed under the terms of the Creative Commons Attribution 4.0 International License (http:// creativecommons.org/licenses/by/4.0/), which permits unrestricted use, distribution, and reproduction in any medium, provided you give appropriate credit to the original author(s) and the source, provide a link to the Creative Commons license, and indicate if changes were made.

\section{References}

Bumajdad A, Eastoe J, Mathew A (2009) Cerium oxide nanoparticles prepared in self-assembled systems. Adv Colloid Interface Sci 147-148:56-66

Choleva TG, Kappi FA, Giokas DL, Vlessidis AG (2015) Paper-based assay of antioxidant activity using analyte-mediated on-paper nucleation of gold nanoparticles as colorimetric probes. Anal Chim Acta 860:61-69

Khattab RY, Arntfield SD (2009) Functional properties of raw and processed canola meal. LWT - Food Sci Technol 42:1119-1124

Kimber DS, McGregor DI (1995) The species and their origin, cultivation and world production. In: Kimber DS, McGregor DI (eds) Brassica oilseeds: production and utilization. CABI Publishing, Wallingford, UK, pp 1-9

Korsvik C, Patil S, Seal S, SelfWT (2007) Superoxide dismutase mimetic properties exhibited by vacancy engineered ceria nanoparticles. Chem Commun 10:1056-1058

Lin M, Fu ZY, Tan HR, Tan JPY, Ng SC, Teo E (2012) Hydrothermal synthesis of $\mathrm{CeO}_{2}$ nanocrystals: Ostwald ripening or oriented attachment? Cryst Growth Des 12:3296-3303

Liu Q, Liu H, Yuan Z, Wei D, Ye Y (2012) Evaluation of antioxidant activity of chrysanthemum extracts and tea beverages by gold nanoparticles-based assay. Colloid Surface B 92:348-352
Maenz DD (2007) Canola protein concentrate for use as a high-valued animal feed ingredient. Feed and Industrial Raw Material: Feed 5: 274-276

Masui T, Hirai H, Imanaka N, Adachi G, Sakata T, Mori H (2002) Synthesis of cerium oxide nanoparticles by hydrothermal crystallization with citric acid. J Mater Sci Lett 21:489-491

Naczk M, Amarowicz R, Sullivan A, Shahidi F (1998) Current research developments on polyphenolics of rapeseed/canola: a review. Food Chem 62:489-502

Naganuma T, Traversa E (2012) Stability of the $\mathrm{Ce}^{3+}$ valence state in cerium oxide nanoparticle layers. Nanoscale 4:4950-4953

Nesi N, Delourme R, Brégeon M, Falentin C, Renard M (2008) Genetic and molecular approaches to improve nutritional value of Brassica napus L. seed. C R Biol 331:763-771

Okuda M, Suzumoto Y, Yamashita I (2011) Bioinspired synthesis of homogenous cerium oxide nanoparticles and two- or threedimensional nanoparticle arrays using protein supramolecules. Cryst Growth Des 11:2540-2545

Ornatska M, Sharpe E, Andreescu D, Andreescu S (2011) Paper bioassay based on ceria nanoparticles as colorimetric probes. Anal Chem 83: 4273-4280

Özyürek M, Güngör N, Baki S, Güçlü K, Apak R (2012) Development of a silver nanoparticle-based method for the antioxidant capacity measurement of polyphenols. Anal Chem 84:8052-8059

Ozyurt D, Demirata B, Apak R (2007) Determination of total antioxidant capacity by a new spectrophotometric method based on Ce(IV) reducing capacity measurement. Talanta 71:1155-1165

Ozyurt D, Demirata B, Apak R (2010) Modified cerium(IV)-based antioxidant capacity (CERAC) assay with selectivity over citric acid and simple sugars. J Food Compos Anal 23:282-288

Ozyurt D, Demirata B, Apak R (2011) Determination of total antioxidant capacity by a new spectrofluorometric method based on Ce(IV) reduction: $\mathrm{Ce}(\mathrm{III})$ fluorescence probe for CERAC assay. J Fluoresc 21:2069-2076

Papadopoulos K, Triantis T, Yannakopoulou E, Nikokavoura A, Dimotikali D (2003) Comparative studies on the antioxidant activity of aqueous extracts of olive oils and seed oils using chemiluminescence. Anal Chim Acta 494:41-47

Pelle FD, González MC, Sergi M, Del Carlo M, Compagnone D, Escarpa A (2015a) Gold nanoparticles-based extraction-free colorimetric assay in organic media: an optical index for determination of total polyphenols in fat-rich samples. Anal Chem 87:6905-6911

Pelle FD, Vilela D, González MC, Sterzo CL, Compagnone D, Del Carlo M, Escarpa A (2015b) Antioxidant capacity index based on gold nanoparticles formation. Application to extra virgin olive oil samples. Food Chem 178:70-75

Roy N, Laskar RA, Sk I, Kumari D, Ghosh T, Begum NA (2011) A detailed study on the antioxidant activity of the stem bark of Dalbergia sissoo Roxb., an Indian medicinal plant. Food Chem 126:1115-1121

Samiee S, Goharshadi EK (2012) Effects of different precursors on size and optical properties of ceria nanoparticles prepared by microwaveassisted method. Mater Res Bull 47:1089-1095

Scampicchio M, Wang J, Blasco AJ, Arribas AS, Mannino S, Escarpa A (2006) Nanoparticle-based assays of antioxidant activity. Anal Chem 78:2060-2063

Shahidi F, Ho C-T (2005) Phenolics in food and natural health products: an overview. In: Shahidi F, Ho C-T (eds) Phenolic compounds in foods and natural health products. American Chemical Society, Washington, DC, pp 1-8

Sharpe E, Frasco T, Andreescu D, Andreescu S (2013) Portable ceria nanoparticle-based assay for rapid detection of food antioxidants (NanoCerac). Analyst 138:249-262

Szydłowska-Czerniak A, Tułodziecka A (2013) Comparison of a silver nanoparticle-based method and the modified spectrophotometric 
methods for assessing antioxidant capacity of rapeseed varieties. Food Chem 141:1865-1871

Szydłowska-Czerniak A, Tułodziecka A, Szłyk E (2012) A silver nanoparticle-based method for determination of antioxidant capacity of rapeseed and its products. Analyst 137:3750-3759

Szydłowska-Czerniak A, Łaszewska A, Tułodziecka A (2015) A novel iron oxide nanoparticle-based method for the determination of the antioxidant capacity of rapeseed oils at various stages of the refining process. Anal Methods 7:4650-4660

Tura D, Gigliotti C, Pedò S, Failla O, Bassi D, Serraiocco A (2007) Influence of cultivar and site of cultivation on levels of lipophilic and hydrophilic antioxidants in virgin olive oils (Olea europea L.) and correlations with oxidative stability. Sci Hortic 112:108-119

Vilela D, González MC, Escarpa A (2012) Gold-nanosphere formation using food sample endogenous polyphenols for in-vitro assessment of antioxidant capacity. Anal Bioanal Chem 404: 341-349

Vilela D, González MC, Escarpa A (2014) (Bio)-synthesis of Au NPs from soy isoflavone extracts as a novel assessment tool of their antioxidant capacity. RSC Adv 4:3075-3081
Vilela D, Castañeda R, González MC, Mendoza S, Escarpa A (2015a) Fast and reliable determination of antioxidant capacity based on the formation of gold nanoparticles. Microchim Acta 182:105-111

Vilela D, González MC, Escarpa A (2015b) Nanoparticles as analytical tools for in-vitro antioxidant-capacity assessment and beyond. Trends Anal Chem 64:1-16

Vuorela S, Meyer AS, Heinonen M (2004) Impact of isolation method on the antioxidant activity of rapeseed meal phenolics. J Agric Food Chem 52:8202-8207

Wang JP, Li NB, Luo HQ (2008) Chemiluminescence determination of ferulic acid by flow-injection analysis using cerium(IV) sensitized by rhodamine 6G. Spectrochim Acta A 71:204-208

Yan M, Wei W, Zuoren N (2007) Influence of pH on morphology and formation mechanism of $\mathrm{CeO}_{2}$ nanocrystalline. J Rare Earths 25: $53-57$

Yoshie-Stark Y, Wada Y, Wäsche A (2008) Chemical composition, functional properties, and bioactivities of rapeseed protein isolates. Food Chem 107:32-39

Zougagh M, Salghi R, Dhair S, Rios A (2011) Nanoparticle-based assay for the detection of virgin argan oil adulteration and its rapid quality evaluation. Anal Bioanal Chem 399:2395-2405 